\title{
«Sie als Arzt!»
}

\section{Enrico Danieli}

Dr. med., Facharzt für Allgemeine Innere Medizin, FMH

Von unseren Patienten werden wir nicht selten an unseren Beruf erinnert. Das ist eine spezielle Situation, je nachdem gut oder weniger gut erträglich. «Sie als Arzt!»: Sie wissen doch, Sie können doch, Sie müssen doch, Sie sollten doch usw. Ein Ausruf, der unsere Dominanz meint, mit unserer Einflussnahme rechnet, der uns Fähigkeiten zuordnet, die wir unter Umständen nicht haben. Immer klingt auch Demonstratives mit, unter Umständen Drohendes; es geht darum, auf der Ebene des Imperativs unsere Macht (als Arzt) zu benutzen oder gar auszunutzen, um für sich als Patient das Beste aus der Begegnung mit dem Arzt herauszuholen.

\section{Wenn der Patient selbst Arzt ist}

Die Situation ändert sich radikal, wenn Sie der Patient sind. Sie als Arzt sind Patient. Sind Sie mehr Patient als Arzt? Oder mehr Arzt als Patient? Auf jeden Fall sind Sie immer beides - leider!

«Sie als Arzt!» Bin ich Patient und benutzt der mich behandelnde Arzt diesen Ausdruck, führt er mich in die Enge. Er stützt sich auf die gemeinsame Berufsbasis. Er arbeitet mit Wissen, das ich wie selbstverständlich haben soll, aber nicht immer meine Spezialitäten abdeckt. Dadurch entlastet sich mein Arzt, er überträgt mir Mitverantwortung, die Schwere der für mich belastenden Situation als Kranker wird entschärft, weil ich mich sozusagen von aussen beobachten kann. Ich werde zum Mitwisser, Mit-Therapeuten. Gleichzeitig, was mich

Ich spiele mit, schütze Detailkenntnisse vor, nur um mich nicht meines medizinischen

\section{Unwissens zu schämen.}

verlockt, bekomme ich eine Bedeutung, die ich in diesem speziellen Gebiet nicht habe.

Doch meine Rolle als «nur» Kranker bin los, ich kann mich nicht mehr verstecken. «Sie als Arzt!» - hätten doch auch wissen müssen (sowieso); und können müssen (natürlich). Und ich? Ich spiele mit, schütze Detailkenntnisse vor, nur um mich nicht meines medizinischen Unwissens zu schämen. Das kann hemmend wirken. Ich bin einverstanden, warte ab, beobachte, verhalte mich passiv. Wenn ich mich dann doch gezwungen fühle, Einwendungen zu erheben, zu fordern, heisst es: «Sie als Arzt, Sie wissen doch um die Harmlosigkeit dieser Symptome.» - natürlich. Oder: «Sie als Arzt, Sie wissen doch, dass diese Symptome unter Umständen fatal sind.» Und weiter bei jedem Untersuchungsschritt: «Sie als Arzt können die Wichtigkeit der Befunde doch einschätzen.»

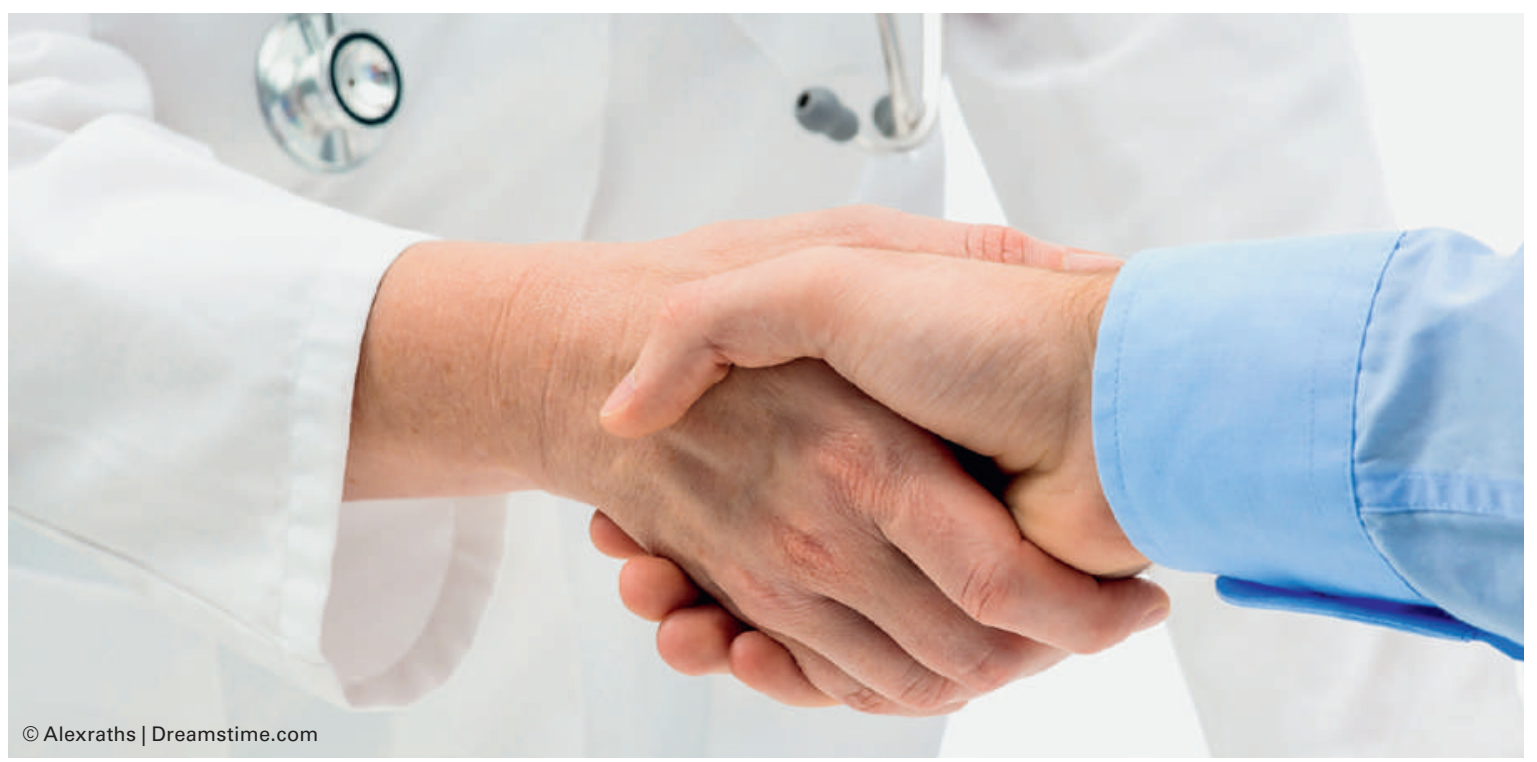

Wenn der Patient selbst Mediziner ist, sind die Rollen beim Arztbesuch nicht mehr klar verteilt: Nicht selten wird Spezialwissen des fachkundigen Patienten vorausgesetzt. 
Immer klingt auch Demonstratives mit, unter Umständen Drohendes; es geht darum, auf der Ebene des Imperativs meinen Status als Arzt zu benutzen oder gar auszunutzen, um für sich als Behandler das Beste aus der Begegnung mit dem Arzt-Patienten herauszuholen. Kenne ich diesen Satz nicht irgendwoher ähnlich?

\section{Ich möchte nur Patient sein}

Was ich auch zu meiner Rettung (wovor?) vorgebe, erklärt haben möchte, alles ist von meinem Beruf abhängig. «Ihnen brauche ich doch nichts zu sagen!» Arzt ein Stigma der Unfreiheit, der Unterwerfung. Es kettet mich fest, lässt mir keinen Raum, und, auf einer anderen Ebene, ordnet mir Verantwortung zu, Verantwortung, die ich nicht tragen will noch kann. Ich möchte doch nur Patient sein. Mich und meinen Körper und noch mehr meine Seele heilenden Händen übergeben, mich befreien von medizinischen Zwängen, ärztlichen Forderungen, mich freisprechen vom ewigen Wissen-Müssen. Doch das gelingt nicht. Etwas steht dazwischen: zwischen Arzt und Arzt. Doch was? Misstrauen - gegenseitig? Man traut sich nicht, fürchtet durchschaut zu werden. Gegenseitig. Warum dann dieses Sich-Verheddern, Sich-Verlieren, manchmal streiten? Löse ich mich los aus meinen Rollen? Von einem Teil von mir selbst? Nein, keineswegs, ich weiss es nicht besser, ich verstehe es nur anders.

Ich wage den Ausbruch. Mich nicht in eine Ecke drängen, mich nicht zähmen lassen durch Statistiken und Durchschnittswerte, verpackt in Floskeln und verab- reicht mit Pflichten. Mich nicht fixieren lassen in der Anonymität, in der alles einebnenden Unpersonifizierung. Da reagiere ich, manchmal ganz entgegen meinem Wesen, laut, heftig: Das geschieht doch alles einzig auf Grund von Daten, nur «lege artis»; dieses «Sie als Arzt müssten doch wissen", dieses «Sie sollten doch wollen» sind doch nur Ausreden (statt Hinwendungen). Es ist dieses Versinken in Zahlen, in Expertenmeinungen, in Beweisen, in Rollen, es ist die alles verschlingende Gleichmacherei, die Entwertung meines Krank-Seins, meine Degradierung als Mensch. Eine Eskalation in Stufen.

\section{Meine letzte Waffe}

Selten wende ich meine letzte Waffe an, versuche mitten ins Herz zu treffen: «Aber Sie, wären Sie denn krank, Sie als Patient, ich meine als Arzt-Patient - würden Sie denn

\section{Die Fatalität meines Berufs wird mich ins Grab} begleiten, denn Arzt ist man auch dann, wenn man es gar nicht sein will, lebenslang.

tatsächlich, könnten Sie denn wirklich ...?» Manchmal hilfts! Gewaltig. Eine Verdoppelung von Medizin - sie wirkt dann als Neutralisation. Und doch: Die Fatalität meines Berufs wird mich ins Grab begleiten, denn Arzt ist man auch dann, wenn man es gar nicht sein will, lebenslang. Dabei wünschte ich mir nur ein wenig Einfühlung, Zuhören, Da-Sein, Engagement über Grenzen hinaus - ganz ohne Arzt sein zu müssen - diesseits/ jenseits. 